\title{
Application of Cathodoluminescence Technique in Light Microscopy to Crystallisation Study of Mold Fluxes
}

\author{
E. Paransky, E. Divry and M. Rigaud \\ CIREP - Chair in Industrial Refractories, Ecole Polytechnique, Montreal, Canada H2M 2N9
}

Mold fluxes are synthetic mixtures based on $\mathrm{SiO}_{2}-\mathrm{CaO}-\mathrm{Al}_{2} \mathrm{O}_{3}$ composition, which are used to cover liquid steel meniscus in the continuous steel casting mold. Molten flux filling the gap between liquid steel and copper mold tends to form partially crystalline film. The degree of crystallinity was found to affect the lubrication and heat transfer properties of the film, and ultimately, the quality of steel [1].

Light Microscopy and SEM/EDS are routinely used to analyse microstructure of the mold flux films. However, low overall hardness and similar chemical compositions of crystal phase and amorphous matrix complicate specimen preparation and hamper reliable recognition of crystal phase by both methods. This work demonstrates the use of cathodoluminescence for microstructural investigtion of crystalline layer in thin films of commercial mold fluxes. Luminoscope ELM-3RX attachment to Nikon Optiphot microscope was employed with electron gun operating at $10 \mathrm{kV}$ and $0.5 \mathrm{~mA}$. Thickness of layers was measured on cathodoluminescence images acquired by SPOT-RT Peltier-cooled digital camera with $1315 \times 1033$ resolution using Image-Pro Plus 4.1 software. The nature of crystalline phase was further analysed employing SEM/EDS (JEOL JSM-840 with LINK software) and XRD (Philips $\mathrm{X}$ 'Pert powder diffractometer).

Figure 1,a is a reflected-light micrograph of cross-section of mold flux film, solidified on the copper substrate after 20 seconds dwell in the molten pool. Some of the crystals are tornout during polishing, while etching tends to introduce artefacts in the porous crystalline zone. On the cathodoluminescence micrograph, taken from the fracture surface, the morphology of crystalline zone in the middle of cross section is revealed more accurately (figure 1,b). The crystals produce intense luminescence of mostly yellow or green colour, while non-luminescent amorphous phase provides the dark background [2]. Nucleation of the first crystals was found to occur on the surface of pores generated by decarburization of the molten flux. After longer dwell times, a continuous crystalline layer is formed, propagating mostly towards the mold face of the film (figure 1,c). The kinetics of crystalline layer growth was evaluated by averaging layer thickness measured on at least 10 representative crosssections. Different morphologies of crystalline zone are observed in the mold fluxes with different initial granulometry and composition of mold powder (figure 2). The major crystalline phase was identified in both cases as cuspidine, $3 \mathrm{CaO} 2 \mathrm{SiO}_{2} \mathrm{CaF}_{2}$.

In this work the technique of cathodoluminescence in reflected-light microscope was found to be an efficient tool of microstructural characterisation of partially crystallised mold fluxes. The difference in contrast between luminescent crystals and non-luminescent (dark) amorphous matrix allows reliable feature recognition and facilitates multiple measurements employing image analysis software.

\section{References}

[1] C.A. Pinheiro et al., Iron \& Steelmaker, February 1995, 37.

[2] D.J. Marshall, Cathodoluminescence of Geological Materials, Unwin Hyman, Boston 1988. 

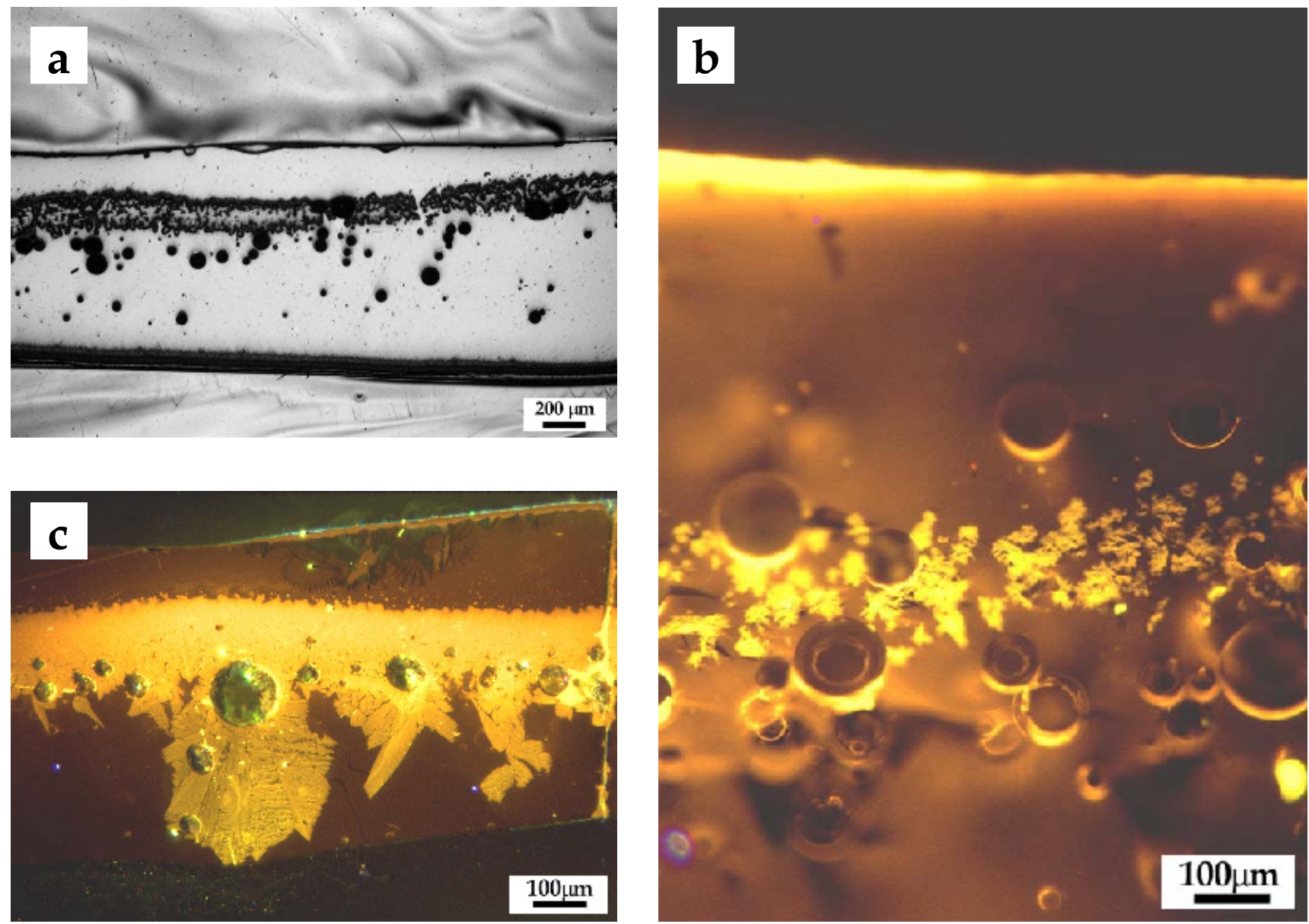

FIG.1: cross-section of a mold flux thin film, $a$ - reflected light, etched; $b$ - cathodoluminescence image from fracture surface; $\mathrm{c}$ - cathodoluminescence image from polished cross-section.
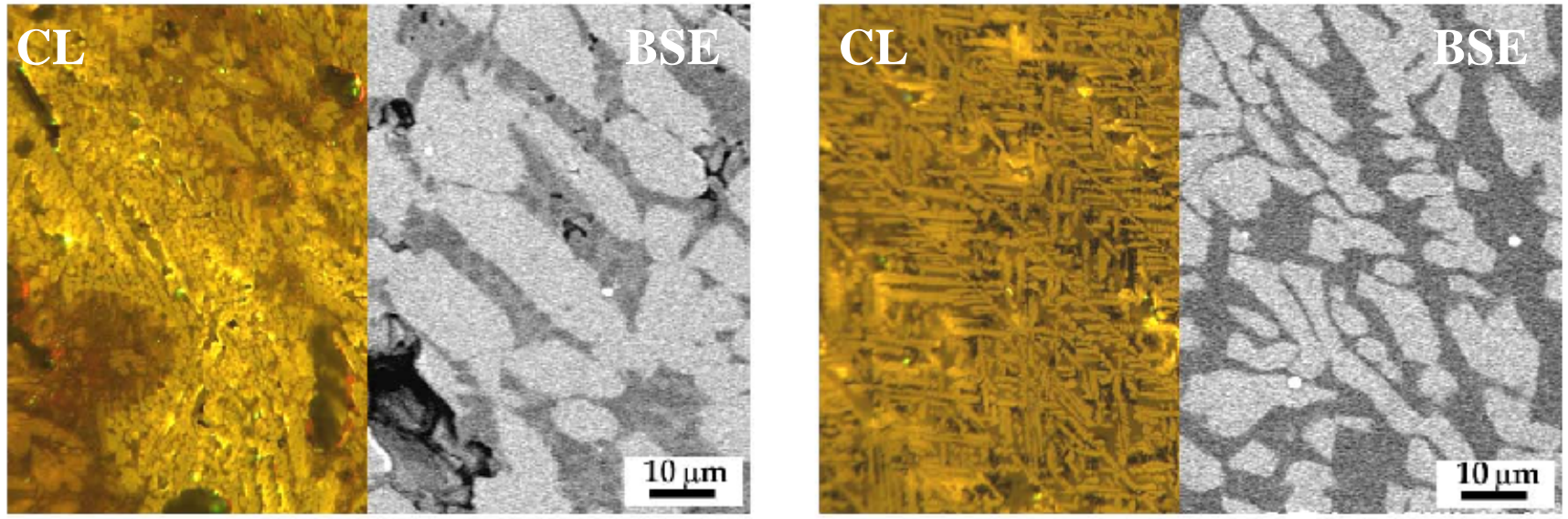

FIG.2: polished surface of two commercial mold flux specimens crystallized by slow cooling. 